\title{
Indução de enraizamento de ora-pro-nobis (Pereskia Aculeata Mill) sob diferentes concentrações de ácido indolbutirico
}

O uso de auxinas sintéticas aumenta a produção de mudas e melhora a uniformidade do enraizamento. Dentre essas, o AlB (ácido indolbutírico) é uma das mais utilizadas. A planta Pereskia aculeata Mill., conhecida como ora-pro-nobis, têm despertado o interesse devido ao elevado conteúdo proteico e a ausência de toxidade de suas folhas. Dentro desse contexto, esse trabalho teve o objetivo de avaliar o efeito de três concentrações do ácido indolbutírico (AIB - 0; 2000 e 4000 mg.L-1) na formação de raízes adventícias em três tipos de estacas caulinares (herbáceas, semi-lenhosas e lenhosas) de ora-pro-nobis (Pereskia aculeata Mill.) para a obtenção de mudas. As concentrações 2000 e 4000 mg.L-1, apresentaram os melhores resultados em número de raízes por estacas semi-lenhosa e lenhosa. Os índices de AIB não interferem no comprimento da raiz e sendo apenas as herbáceas os propágulos com menor comprimento de raiz.

Palavras-chave: Auxina; Enraizamento de plantas; Fitormônios; Pereskia aculeata Mill.

\section{Rooting induction of ora-pro-nobis (Pereskia Aculeata Mill) under different concentrations of indolbutyric acid}

The use of synthetic auxins improves seedlings production and roots uniformness. Among these auxins, AlB (indolebutyric acid) is one of the most used. The plant Pereskia aculeata Mill. (ora-pro-nobis), have aroused the interest of the food industry due to the high protein content and the absence of toxicity in its leaves. In this context, this work aimed to evaluate the effect of three AIB concentrations ( 0,2000 and $4000 \mathrm{mg} . \mathrm{L}-1)$ on adventitious roots production in three types of stem cuttings (herbaceous, semi-woody and woody) of ora-pro-nobis (Pereskia aculeata Mill.) to obtain seedlings. 2000 and 4000 mg.L-1 concentrations presented the best results in number of roots in semi-woody and woody cuttings. AlB do not interfere in root length and the herbaceous cuttings presented the smalest root length.

Keywords: Auxin; Rooting plants; Phytohormones; Pereskia aculeata Mill.

Topic: Desenvolvimento, Sustentabilidade e Meio Ambiente

Reviewed anonymously in the process of blind peer
Received: 04/12/2020

Approved: 21/02/2021
Lucas Vasconcelos Rocha

Universidade Federal Rural do Rio de Janeiro, Brasil http://lattes.cnpq.br/4742366559699803

http://orcid.org/0000-0002-9377-1685

lucas.vasconcelos3@gmail.com

José Barbosa de Souza Júnior

Universidade Federal Rural do Rio de Janeiro, Brasil

http://lattes.cnpq.br/9300265571658603

http://orcid.org/0000-0001-5930-1009

josebarbosa-jr@hotmail.com

Rafael Gomes da Mota Gonçalves

Universidade Federal Rural do Rio de Janeiro, Brasil

http://lattes.cnpq.br/0244672026134100

http://orcid.org/0000-0001-9541-6698

rafaelmotag@gmail.com

\author{
Julia Barra Netto Ferreira \\ Universidade Federal de Lavras, Brasil \\ http://lattes.cnpq.br/3256795822420447 \\ http://orcid.org/0000-0003-3599-567X \\ julia bnf@hotmail.com \\ João Sebastião de Paula Araújo (iD \\ Universidade Federal Rural do Rio de Janeiro, Brasil \\ http://lattes.cnpq.br/4668715535047425 \\ http://orcid.org/0000-0003-4970-9443 \\ rafaelmotag@gmail.com \\ Ricardo Mota Miranda \\ Universidade Federal Rural do Rio de Janeiro, Brasil \\ http://lattes.cnpq.br/3898126903821400 \\ rafaelmotag@gmail.com
}

Referencing this:

ROCHA, L. V.; SOUZA JUNIOR, J. B.; GONÇALVES, R. G. M.; FERREIRA, J. B. N.; ARAUJO, J. S. P.; MIRANDA, R. M.. Indução de enraizamento de ora-pro-nobis (Pereskia Aculeata Mill) sob diferentes concentrações de ácido indolbutirico. Nature and Conservation, v.14, n.1, p.101-106, 2021. DOI: http://doi.org/10.6008/CBPC2318-2881.2021.001.0011 


\section{INTRODUÇÃO}

Devido ao grande avanço da ciência e a necessidade de produção cada dia mais elevada, surge a perspectiva de utilizar na produção de mudas os reguladores vegetais de crescimento, capazes de promover o aumento da porcentagem de estacas enraizadas, encurtar o tempo de formação das raízes e consequentemente, diminuir o custo de produção (ALVARENGA et al., 1983). Dentre as auxinas sintéticas, o AIB (ácido indolbutírico) é uma das mais utilizadas.

A espécie Pereskia aculeata Mill. (cactaceae), também conhecida como ora-pro-nobis, lobrobó e trepadeira limão, é nativa do Brasil, muito comum nas regiões de caatinga, cerrado e mata atlântica (BARBOSA, 2012). Devido a sua rusticidade, adapta-se muito bem aos diversos tipos de solo, não sendo exigente em fertilidade (BRASIL, 2010). É classificada botanicamente como uma planta perene, de habito aéreo escandente. Apresenta caules finos com ramos longos semi-lenhosos e lenhosos com a extremidade herbácea, possui acúleos ao longo desses ramos, encontrado aos pares, curtos e curvos. As folhas são lisas, longas, suculentas, coloração verde escuro, formato elíptico, com cerca de sete centímetros de comprimento e quatro centímetros de largura na região mediana do limbo e pecíolo curto. As flores são pequenas e de coloração branca, com a parte central alaranjada (BRASIL, 2010; MADEIRA et al., 2013), os frutos são pequenas bagas espinhosas, esféricas, de coloração amarela quando maduros (BRASIL, 2010; MARSARO JÚNIOR et al., 2011; MADEIRA et al., 2013); com presença de mucilagem na planta (ALBUQUERQUE et al., 1991).

A espécie Pereskia aculeata é considerada uma planta alimentícia não convencional. É comumente utilizada na alimentação em vários Estados do Brasil. As folhas, por apresentarem alto teor de proteína e fibras (KAZAMA et al., 2012), ausência de toxicidade e presença significativa de ferro e cálcio (KAZAMA et al., 2012) podem ser uma alternativa para o enriquecimento e incremento da alimentação.

É relatada como de fácil propagação via estaquia caulinar, com facilidade em enraizamento, crescimento rápido e vigoroso. Não é exigente por solos férteis, adapta-se melhor sob a luz solar plena, além de ter histórico de baixa incidência de pragas e doenças.

Fazer tratamento de estacas com auxinas sintéticas pode estimular o surgimento de raízes e aumentar a produção de mudas com mais qualidade fisiológica em menor espaço de tempo, além disso, aumenta a uniformidade do enraizamento (BOLIANI et al., 1998). Em função desse fato, esse trabalho objetivou-se avaliar o efeito de três concentrações do fitoregulador ácido indolbutírico (AIB - 0; 2000 e 4000 mg.L-1) para analisar a formação de raízes adventícias em três tipos de estacas caulinares (herbáceas, semilenhosas e lenhosas) de ora-pro-nobis (Pereskia aculeata Mill.) para a obtenção de mudas.

\section{MATERIAIS E MÉTODOS}

O experimento foi conduzido na Universidade Federal Rural do Rio de Janeiro (UFRRJ), setor de Horticultura situado na latitude $22 \circ 45^{\prime} \mathrm{S}$, longitude $43 \circ 41^{\prime} \mathrm{W}$ Grw e altitude de $33 \mathrm{~m}$, sendo o clima incluído como do tipo Aw na classificação de Köppen. 
Os materiais propagativos avaliados foram coletados no dia 05 de Setembro de 2018, de plantas matrizes localizadas na Fazendinha Agroecológica Km 47, no município de Seropédica, RJ. As estacas foram classificadas em herbáceas, semi-lenhosas e lenhosas, considerando o grau de lignificação.

O tamanho das estacas foi padronizado em torno de $20 \mathrm{~cm}$. As estacas foram desfolhadas, e em seguida cortou-se em bisel a extremidade basal de cada estaca. As estacas foram desinfestadas imergindoas em solução de hipoclorito à $1 \%$ por um minuto. Posteriormente, suas extremidades inferiores foram tratadas com soluções de ácido indolbutírico (AIB) em diferentes concentrações (0, 2000 e 4000 mg.L-1) por dez segundos, após o tratamento as estacas então foram levadas ao propagador, onde foram estaqueadas a cerca de $1 / 4$ de seu comprimento, utilizando areia grossa lavada como substrato. A irrigação foi realizada por meio de nebulização intermitente com ativação automática a cada 30 minutos.

Para a implantação do experimento utilizou-se esquema fatorial $3 \times 3$ (concentração AIB $\times$ tipo de estaca) e o delineamento foi do tipo Blocos casualizados com 3 repetições. Cada parcela experimental constou de 10 estacas, totalizando 270 estacas.

Foram avaliadas em cada estaca o número de raízes e o comprimento da maior raiz, além de presença de brotação e eventual morte da estaca. As médias dos tratamentos foram submetidas ao teste de Tukey com nível de significância de 5\%, utilizando-se os programas Rbio e R statistic.

\section{RESULTADOS E DISCUSSÃO}

Avaliando as variações de concentração do ácido indolbutirico (AIB) nas estacas pode-se perceber que há relação entre a aplicação das doses de 2000 e $4000 \mathrm{mg} \mathrm{L}^{-1}$ tanto para o número de raízes quanto para o comprimento da maior raiz (Tabela 1). Além disso percebe-se variações entre a idade escolhida da estaca para a propagação, herbáceas, semi-lenhosa e lenhosa em todos os quesitos avaliados.

Tabela 1: Efeito da interação dos diferentes tipos de concentrações de Ácido Indolbtírico (AIB) em diferentes tipos de estacas de Pereskia Aculeata Mill., como base nos percentuais de estacas vivas, enraizadas, com brotação, média de raízes por estacas e de comprimento da maior raiz.

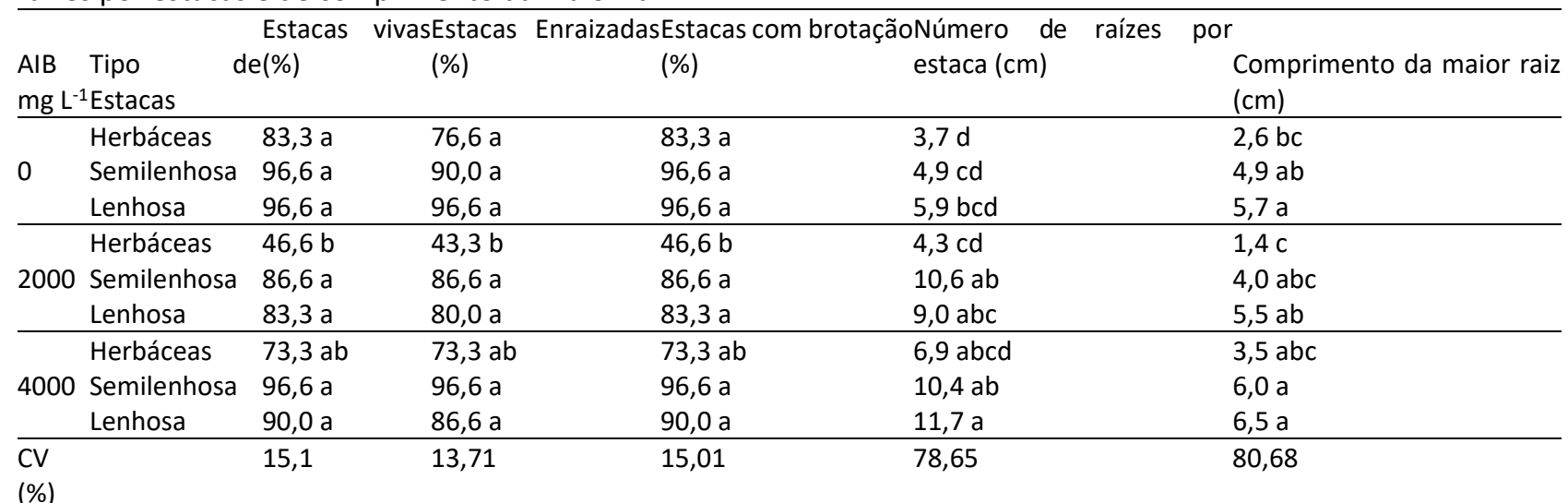

Médias na coluna, seguidas da mesma letra, não diferem entre si, pelo teste de Tuckey $(p>0,05)$.

As condições fisiológicas das estacas é um dos fatores preponderantes em relação ao enraizamento das estacas, destacando-se a presença de carboidrato, substâncias nitrogenadas, auxinas e compostos fenólicos. A posição da coleta, a juvenilidade, a presença de folhas e gemas, o período e a idade da planta 
matriz e fatores ambientais também podem influenciar no sucesso da propagação (HESS, 1969; HARTMANN et al., 1996).

$\mathrm{Na}$ Figura, percebe-se que as estacas semi-lenhosas e lenhosas obtiveram os maiores resultados de número de raízes por estaca quando tratadas a concentração de 2000 e $4000 \mathrm{mg} \mathrm{L}^{-1}$ de AlB do que quando comparada aos propágulos herbáceos.

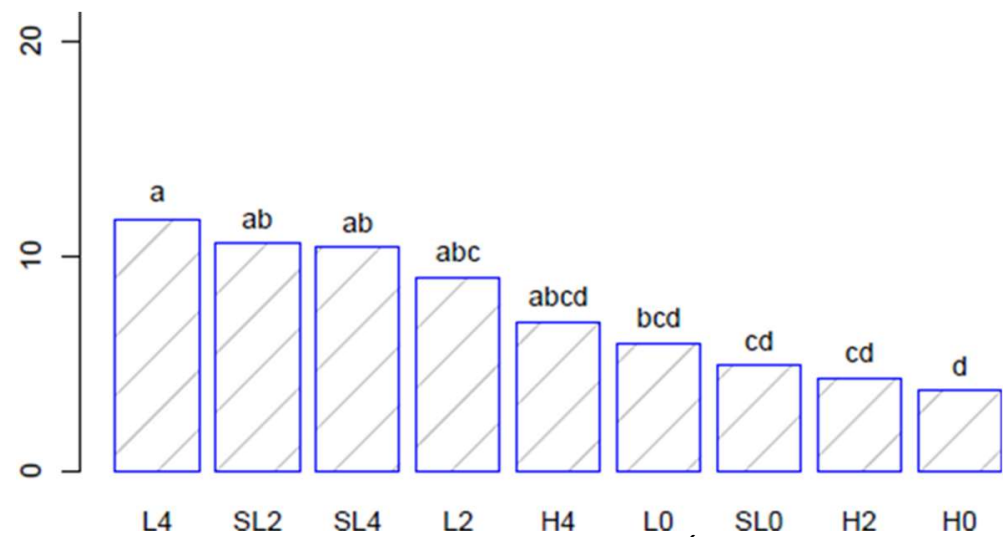

Figura 1: Efeito da interação dos diferentes tipos de concentrações de Ácido Indolbtírico (AIB) em diferentes tipos de estacas de Pereskia Aculeata Mill., como base na média de raízes por estaca. $\mathrm{H}=$ herbáceas, $\mathrm{SL}=$ semi-lenhosa, $\mathrm{L}=$ lenhosa, $0=$ controle, $2=2000$ de AIB e $4=4000 \mathrm{mg} \mathrm{L}^{-1}$ de AIB.

Isso se deve pelo fato de que o grau de lignificação das estacas lenhosas e semi-lenhosas facilitam seu manejo além de proporcionar maior tempo de vida útil do propágulo Hartmann et al. (1996), além do uso de auxina poder induzir o surgimento de raízes em algumas plantas (BOLIANI et al., 1998).

Quando se analisa a média do comprimento da raiz percebe-se que independente da dose de AIB tratada os propágulos lenhosos e semi-lenhosos não se diferenciaram, porém os herbáceos apresentam os mais baixos índices (Figura 2).

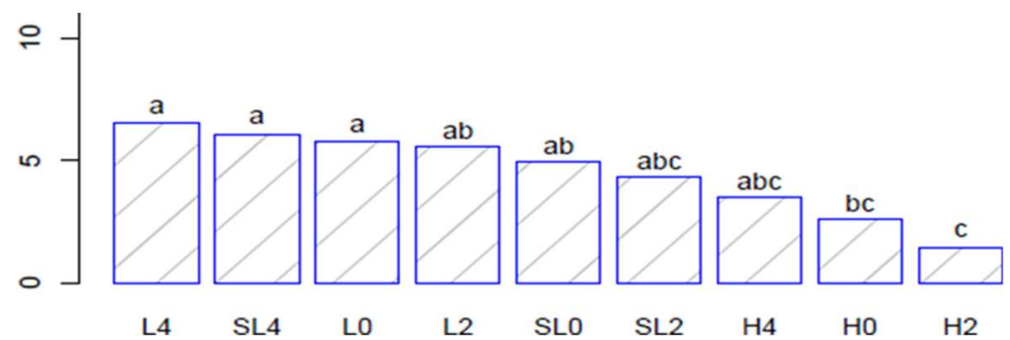

Figura 2: Efeito da interação dos diferentes tipos de concentrações de Ácido Indolbtírico (AIB) em diferentes tipos de estacas de Pereskia Aculeata Mill., como base no comprimento da maior raiz. $\mathrm{H}=$ herbáceas, $\mathrm{SL}=$ semi-lenhosa, $\mathrm{L}=$ lenhosa, $0=$ controle, $2=2000$ e $4=4000 \mathrm{mg} \mathrm{L}^{-1}$ de AlB.

Pode-se dizer que as doses de AIB não influenciaram o comprimento das raízes, segundo Monteiro et al. (2009), o efeito das dosagens dos fitoreguladores pode ser tóxico e inibir o crescimento das raízes em alguns casos. Porém a idade dos propágulos foi um fator determinante como visto nos resultados obtidos pelas herbáceas.

O efeito da interação com base na porcentagem de estacas vivas demonstra que a concentração de AIB não interfere entre os propágulos semi-lenhosos e lenhosos para sobrevivência dos mesmos, mas para as estacas herbáceas houve diferença, sendo que apenas o tratamento controle, que não recebeu nenhuma dose de AIB (Figura 3, I.) apresentou os maiores índices de vitalidade após plantio quando comparados aos 
tratamentos de herbácea com 2000 e 4000 mg L-1 de AlB.
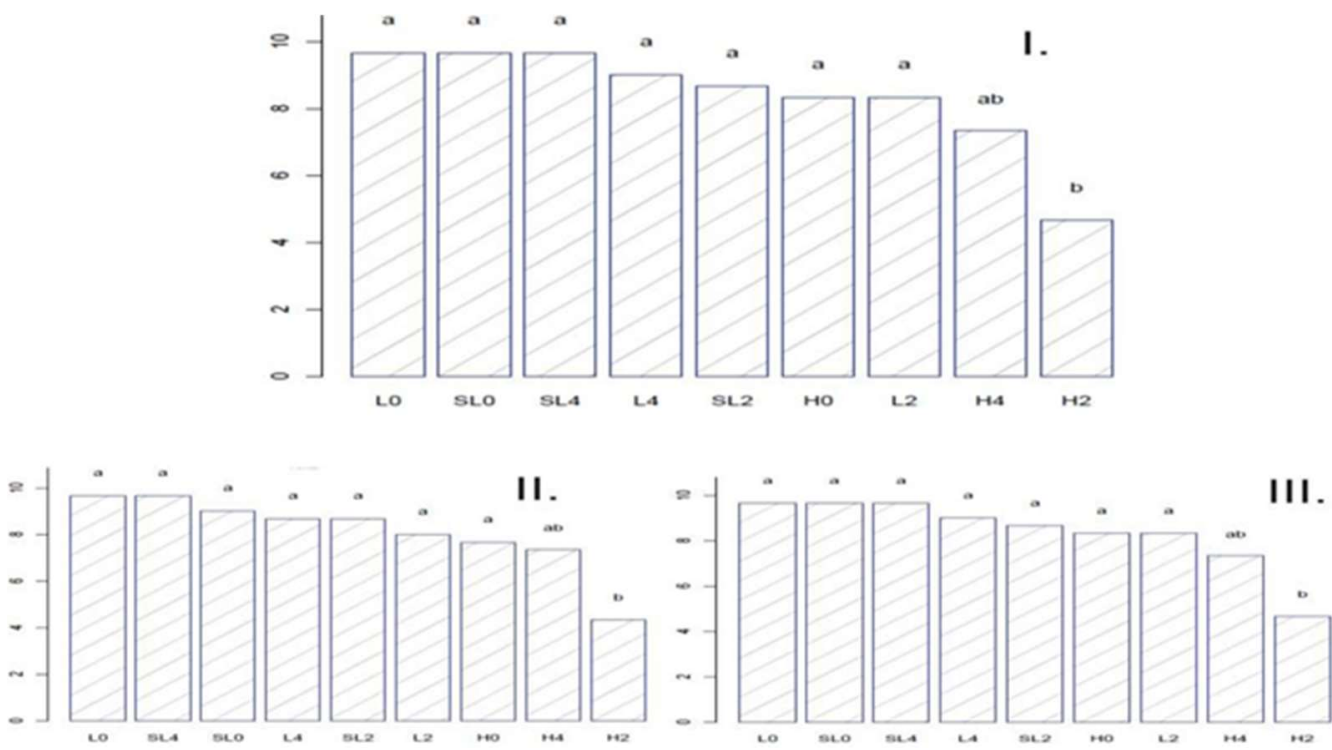

Figura 3: Efeito da interação dos diferentes tipos de concentrações de Ácido Indolbtírico (AIB) em diferentes tipos de estacas de Pereskia Aculeata Mill., como base na \% de estacas vivas (I.) \% de enraizamento (II.) e \% de brotação (III.). H $=$ herbáceas, $\mathrm{SL}=$ semi-lenhosa, $\mathrm{L}=$ lenhosa, $0=$ controle, $2=2000$ e $4=4000 \mathrm{mg} \mathrm{L}^{-1}$ de AlB.

Em relação ao percentual de enraizamento é analisado o mesmo padrão da porcentagem de estacas vivas, sendo as herbáceas novamente com os menores índices (Figura 3, II.). A porcentagem de brotação também apresentou resultados semelhantes, onde apenas propágulos herbáceos tratados com 2000 ppm de AIB obtiveram resultados significativamente menores na média de porcentagem de brotação, como mostra a (Figura 3, III.).

\section{CONCLUSÕES}

As concentrações 2000 e 4000 mg. $\mathrm{L}^{-1}$, apresentaram os melhores resultados em número de raízes por estacas semi-lenhosa e lenhosa. Os índices de AIB não interferem no comprimento da raiz e sendo apenas as herbáceas os propágulos com menor comprimento de raiz. O fito-regulador AIB nas concentrações 2000 e $4000 \mathrm{mg} / \mathrm{L}^{-1}$ não influenciou no enraizamento de estacas, no comprimento de raízes e numero de brotações; influenciou apenas no numero de raízes.

O fator que induziu a viabilidade das estacas foi o grau de lignificação, sendo as estacas lenhosas e semi-lenhosas com resultados superiores em relação às herbáceas, em todos os quesitos. Recomenda-se a propagação de Pereskia Aculeata Mill. sem a necessidade de utilização de fito-hormônio além da preferência por propágulos mais lignificados.

\section{REFERÊNCIAS}

ALBUQUERQUE, M. G. P. T.; SABAA-SRUR, A. U. O.; FREIMAN, L. O.. Composição centesimal e escore de aminoácidos em três espécies de ora-pro-nobis (Pereskia aculeata Mill., P. bleu De Candole e P. pereskia (L) Karsten). Boletim SBCTA, v.25, n.1, p.7-12, 1991.
ALVARENGA, L. R.; CARVALHO, V. D.. Uso de substâncias promotoras de enraizamento de estacas frutíferas. Informe Agropecuário, Belo Horizonte, v.9, n.101, p.47-55, 1983.

BARBOSA, C. K. R.. Manejo e conservação pós-colheita de Pereskia aculeata Mill. Dissertação (Mestrado) Universidade Federal de Viçosa, Viçosa, 2012. 
BOLIANI, A. C.; SAMPAIO, V. R.. Efeitos do estiolamento basal e do uso do ácido indolbutírico no enraizamento de estacas de nespereira (Eriobotrya japonica Lindley). Cultura Agronômica, v.7, n.1, p.51-63, 1998.

BRASIL. Ministério da Agricultura, Pecuária e aAbastecimento. Secretaria de Desenvolvimento Agropecuário e corporativismo. Manual de Hortaliças não convencionais. Brasília: MAPA, 2010.

FERRIANI, A. P.; BORTOLINI, M. F.; ZUFFELLATO-RIBAS, K. C.; KOEHLER, H. S.. Propagação vegetativa de estaquia de azaléia arbórea (Rhododendron thomsonii). Ciências Agrárias, v.27, n.1, p.35-42, 2006.

HARTMANN, H. T.; KESTER, D. E.; DAVES JUNIOR, F. T.; GENEVE, R. L.. Plant propagation principle and practices. 6 ed. New Jersey: Prentice-Hall, 1996.

HESS, C. E.. International and external factors regulating root initiation: root growth. London: Buttersworth, 1969.
KAZAMA, C. C.; UCHIDA, D. T.; CANZI, K. N.; SOUZA, P.; CRESTANI, S.; JUNIOR, A. G.; JUNIOR, A. L.. Involvement of arginine-vasopressin in the diuretic and hypotensive effects of Pereskia grandifolia Haw. (Cactaceae). Journal of Ethnopharmacology, v.144, n.1, p.86-93, 2012.

MADEIRA, N. R.; SILVA, P. C.; BOTREL, N.; MENDONÇA, J. L.; SILVEIRA, G. S. R.; PEDROSA, M. W.. Manual de produção de hortaliças tradicionais. Brasília: Embrapa, 2013.

MARSARO JÚNIOR, A. L.; SOUZA FILHO, M. F.; ADAIME, R.; STRIKIS, P. C.. Flrst report of natural infestation of Pereskia aculeata Mill. (cactaceae) by Ceratitis capitata (Wedemann) (diptera: Tephiritidae) in Brazil. Revista de Agricultura, v.86, n.2, p.151-154, 2011.

MONTEIRO, J. G.; WISINTAINER, C.; REY, M. S.. Enraizamento de estacas de batata-doce. In: SEMINÁRIO DE INICIAÇÃO CIENTIFICA DA UNIVERSIDADE ESTADUAL DE GOIÁS, 7. Anais. Anápolis, 2009.

A CBPC - Companhia Brasileira de Produção Científica (CNPJ: 11.221.422/0001-03) detém os direitos materiais desta publicação. Os direitos referem-se à publicação do trabalho em qualquer parte do mundo, incluindo os direitos às renovações, expansões e disseminações da contribuição, bem como outros direitos subsidiários. Todos os trabalhos publicados eletronicamente poderão posteriormente ser publicados em coletâneas impressas sob coordenação da Sustenere Publishing, da Companhia Brasileira de Produção Científica e seus parceiros autorizados. Os (as) autores (as) preservam os direitos autorais, mas não têm permissão para a publicação da contribuição em outro meio, impresso ou digital, em português ou em tradução. 